\title{
Analysis of the Third Movement of "Scheherazade"by Rimsky-Korsakov
}

\author{
Huan-Hao ZHANG \\ No.108 of Changanzhong Road Yanta District Xi'an Shaanxi province \\ Piano Department Of Xi'an Conservatory of Music \\ piano_hao@163.com
}

Key words: Rimsky; Shehrachard; heaven and earth; song structure: harmony; composition techniques

\begin{abstract}
The Arabian Nights", also known as "Shechra Chard", is the 19th century Russian composer Rimsky representative works, this article through the third part of the work of the piano version of the piano version of the analysis, Composer techniques, harmony layout, tonal layout, the study of the law, the depth of mining works of the creative skills, in order to understand this era of Russian music works to provide valuable clues.

Rimsky Korsakov is an outstanding composer in Russia in nineteenth Century. Moussorgski, Borodin, Balakirev, CesarCui and Rimskyfored the strong group. Their music is very influential at that time, they have made a great contribution to Russian music. Rimsky was born ina noble family. He is also a naval officer, composer, music educator. He has different identities at the same time, which make him a special person. His works still have fresh vitality today .He also trained Prokofiev, Stravinsky and some other great excellent composers. "Scheherazade” is one of Rimsky's masterpieces. "Scheherazade" is also called Arabian Night. The article will analysis the third movement of "Scheherazade". This piece is selected from one thousand and one nights. This piece is slight and gentle with Arabia style which tell a warm love story of the prince and princess.
\end{abstract}

This piece is a sonata form without development.

Exposition: The first tonal area A: a period of two parallel phrases

The tonic chord that starts from the theme of $G$ major indicates the modal tonality. The theme motivation is different from the previous sonata form. In the past, the theme of heroism was adopted frequently, while the song adopted the gentle Arabia style, and the melody was broad and gentle. The theme of the first tonal area use the music material of second sequence, interspersed with the combination of dotted eight note and sixteen note, which make the original broad gentle melody line more lively. The phrases go like the declarative, which continue to strengthen the theme of the similar melody. In the base, the long chords are used as the support of the melody, while the use of the combination of the steps makes the melodic lines elongate, deep and long. The eighth bar is a perfect cadence. After entering the phrase of A2, tonality turns frequently. In the first half of the phrase of A2 tonality turn from G major to e minor. The tonality of the second half of A2 turns to subdominant minor of G, and few changes the use of music, melody is full of Arabia style. The accompaniment still uses the column chord, with the note becomes shorter, the low tone melody line goes down into scale, which is more flowing. In bar 20, it is a perfect cadence in the tonic chord. After that, four bars of supplemented by continuous step movements bring the first tonal area A 'period.

The first tonal area $\mathrm{A}$ 'is a change of the first tonal area $\mathrm{A}$, the tonality turns into the major of dominant $\mathrm{G}$. The first tonal area $\mathrm{A}^{\prime}$ is similar to the first tonal area $\mathrm{A}$, using the same narrative techniques. Melody is more clear and quiet which shows the prince's gentle and elegant image. The repeat of period A ', not only further consolidate the theme, the change of the tone making the theme more fresh. The accompaniment uses the column chord, and adds melody line to the inner voice, which makes the music image more vivid and interesting $C$. This section adopts the same cadence as the first tonal area A. After the perfect cadence, 4 bars bring the transition out.

\section{Transition: a Transition Omits the Import}

Center: center section is the connection of the theme of the first tonal area and the sequence of steps 
up and down in supplement, which has the characteristics of fragmentation,

It helps to promote the development of music. The tonality of transition turns into B flat major, which has a sharp contrast. The tonality of the 52nd bar turns into A flat major, flat tone contrast between the center section, After the 58th bar, it go back to B flat major again. From bar 60 to 65 the repeating $\mathrm{F}$ of the base is preparing for the second tonal area. Breaking into the end of the transition brings the second tonal area out.

\section{The Second Tonal Area: a Period of Two Parallel Phrases}

The entire second tonal area B start in B major, and the tonic chord at the beginning of the B segment indicates the tonality. On the musical material, the second tonal area B uses the material very similar to the first tonal area A. Two music equally charming in rhythm and tone is very similar, the second tonal area B use a lot of sound playing method, makes the character more enthusiastic and lively . This material, similar to the use of musical personality, portrayed the prince and princess as a perfect image . The use of B phrase and theme of very similar material, using different playing methods, using a large number of skip, embody different music, accompaniment by column chords, accompanied by a continuing tone repetition, and its melody playing method complement each other. The latter phrase to minor reduction $B$ off $G$ minor, perfect ending in a chord. B1 phrase is repeated octaves to play B music, accompaniment is still accompanied by repeated column chords played the sound. Deepen the image of the theme of the second tonal area.A perfect cadence finish the whole second tonal area B.

\section{Close}

The close reviews the whole piece. The central section of the end of the song integrates the most characteristic parts of the the first tonal area A and the secondtonal area B. In bar 84-87, the two parts of the the first tonal area and the extreme scale are merged and divided, which makes the music development have a strong dynamic. The bar 88-91 and the similar material its playing method, highlight the characteristics of the secondary theme. The 123 section is the center in this part of the main department before, after the part is alternately deputy department characteristics, in almost no division development, continue to be the "round" climax. The tonality of the paragraph is also very unstable. The end to side cut in $\mathrm{B}$ direction is minor in $\mathrm{F}$ minor in $\mathrm{F}$ minor, then transferred under the direction of minor (side cut in B minor, a minor) into the same name in B flat major; the relationship after the turn of $\mathrm{F}$ minor A flat ended in A flat major subordinate direction in D. At the end of the 120-124 section, the injection method reviews and ends the whole presentation, leading to the recapitulation.

\section{Recapitulation}

The recapitulation of this piece is a motivated recapitulation .It has a great difference compared to the exposition. After a series of split development, the music is pushed to a climax. The first tonal area A2: is a period of two parallel phrases. There are 5 bars cadenza behind the A5. The first tonal area A3 is different from the A1, which is a motivated recapitulation. The first tonal area A3 combines the new expansion of the new material with the theme motivation, and changes the chord of the accompaniment to make the melody lines more flowing and wider. After the perfect cadence with the major chord ,transition is coming.

\section{The Transition: A Ransition Omits The Import and The Preparing}

The center section starts with the material of repeated octave in the first tonal area . After the perfect cadence, there is a big supplement, which is fragmented. The ff pushes the transition into climax. Breaking into the end of the transition brings the second tonal area B' out.

The second tonal area B' is a period of two parallel phrases. This period reflects the sonata form 
of tonal regression principle, starting in $\mathrm{G}$ major. When the melody comes into play, it repeats the state of octaves, which is very exciting. In addition, the accompaniment becomes a broken chord. And the low voice always has the continuous sound to make the long sound harmony cushion, and consolidates the tonality. After using the split development techniques, expansion of the B2. With the split development of music, the accompaniment changed from decomposition to semi decomposition and column and chord combined with repeated playing, which made the music excited and reached the climax of $\mathrm{B}$. The material part and the $\mathrm{B}$ phrase by the split way fragmentation B1 phrase, the climax of the music, while the latter part of the soft down, vice B 'to complete the termination and finally ended a chord.

\section{Close}

Still use the theme of the first tonal area to do a summary review of the whole work. The accompaniment is mainly based on the broken chord, and the repetition of the leading tone in the low tone, which terminates perfectly in the tonic chord. After the perfect cadence, a 4 bars small coda using the sound shape of the main material of the piece reviews the piece, and the whole work is finished.

\section{Conclusion}

This article from the tone of harmony, material motivation, etc., the analysis of the "Shechra Chad" the third movement of the composition techniques. But also a profound understanding of the 19th century Russian music as a whole style and popular elements [5], hope that this analysis can be for the same period of music or Rimsky music to provide some clues.

\section{References}

[1] Yu Runyang. "History of Western music" [M]. Shanghai Music Publishing House, 2005.

[2] Paul Long Doric. Western Music History [M]. Beijing: People's Music Publishing House, 1989.

[3] Qian Renkang . Music works analysis tutorial. [M]. Shanghai Music Publishing House. 2001

[4] Li Zhenhua. "Introduction to Music Analysis and Creation" [M]. Baihua Literature and Art Publishing House, 2006.

[5] Rimsky Korsakov. Wu Peihua translation. My music life [M]. Music Publishing House .1962 